\title{
História do ciclismo em Porto Alegre: 05 altos e baixos de uma prática
}

\author{
cycling history in Porto Alegre city: \\ the ups and downs of a practice
}

Carolina Fernandes da Silva, ${ }^{1}$ Eduardo Klein Carmona, ${ }^{1}$ Janice Zarpellon Mazo. ${ }^{1}$

'Universidade Federal do Rio Grande do Sul (UFRGS), Porto Alegre, RS, Brasil.

Recebido em: abril 2015 / Aceito em: abril 2015

carol_ed.fis@hotmail.com

\section{RESUMO}

O ciclismo é um esporte de origem europeia, que pode ser definido como a prática das corridas de bicicleta. No decorrer do século XIX ocorreu sua difusão para outros continentes, chegando ao Brasil e ao estado do Rio Grande do Sul na segunda metade do século. Objetivo: historiar desde as primeiras provas ciclísticas em Porto Alegre, passando pelo arrefecimento das disputas, até os anos de 1930, quando são retomadas as provas ciclísticas na cidade. Método: análise documental de publicações acerca do ciclismo em jornais do Rio Grande do Sul que circulavam na transição do século XIX e primeira metade do século XX. Resultados e Discussão: no princípio, a prática ciclística era promovida por dois clubes de Porto Alegre, que rivalizavam disputas acirradas. Ambos possuíam locais próprios para a prática, os velódromos. No final da década de 1910, o ciclismo teve um declínio com o advento do futebol, a novidade esportiva da época. Após um período em baixa, o esporte ganha um novo fôlego na década de 1930. Novos clubes haviam sido formados e a prática não estava mais restrita à capital, ocorriam também no interior, principalmente na cidade de Pelotas. A partir do fim do século XIX, as competições passaram a ter notas frequentes no jornal A Federação. Além disso, houve a criação de uma entidade própria, a Federação Gaúcha de Ciclismo, em 1935, que, posteriormente, também incorporou a prática do motociclismo. Considerações finais: historicamente, o ciclismo faz parte do cenário esportivo sul-rio-grandense, mas, ao longo do tempo, sofreu períodos de ascensão e declínio nas primeiras décadas do século $X X$.

Palavras-chave: Ciclismo; História do esporte; Clubes.

\section{ABSTRACT}

Cycling is a sport with European origin, which can be defined as the practice of bike racing. Cycling dissemination to other continents occurred during the 19th century, arriving in Brazil and the state of Rio Grande do Sul in the second half of the century. Objective: to write a history since the earliest cycling evidence in Porto Alegre, through the dispute weakening until the 1930s, when they resumed the cycling events in the city. Method: documentary analysis of publications about cycling in Rio Grande do Sul newspapers which circulated from the late 19th century to early twentieth century. Results and Discussion: at the beginning the cycling practice was promoted by two clubs of Porto Alegre, which rivaled close races. Both had their own places for practice called cycle tracks. In the late 1910, cycling had a decline with the advent of football, sport novelty at the time. After a down period, the sport gained new life in the 1930. New clubs had been formed and the practice was no longer restricted to the capital, also occurred in the state hinterland, especially in the city of Pelotas. From the late 19th century, the competitions began to have frequent notes in the local newspaper A Federação. In addition, there was the creation of a separate entity, the Gaucho Cycling Federation in 1935, which later also incorporated the practice of motorcycling. Final considerations: historically, cycling is part of Rio Grande do Sul sports scene, but eventually he suffered periods of rise and decline specially in the first decades of the twentieth century.

Keywords: Cycling; Sports history; Clubs. 


\section{INTRODUÇÃO}

O ciclismo foi um esporte que se disseminou pelo mundo a partir da Europa'. Este esporte pode ser definido como: a prática das corridas de bicicleta. A bicicleta é um veículo de locomoção secular criado para fins de transporte e passeio. Porém, paralelamente a essas utilizações, a prática do ciclismo absorveu elementos de esporte moderno, ou seja, passou por um processo de esportivização.

No Brasil, os primeiros registros acerca da presença e utilização de bicicletas datam da segunda metade do século $\mathrm{XIX}^{2,3}$, tanto na capital do país na época, a cidade do Rio de Janeiro, quanto no estado do Rio Grande do Sul, caso do presente estudo. A prática do ciclismo em Porto Alegre, capital sul-rio-grandense, foi institucionalizada em clubes no final do século XIX. Inicialmente, as disputas ocorriam nas ruas ou nos hipódromos até a conclusão dos velódromos ${ }^{4}$.

Os dois primeiros clubes de Porto Alegre construíram velódromos, onde rivalizavam disputas ciclísticas ${ }^{5}$. No princípio do século $X X$, os velódromos passaram a sediar práticas de outros esportes, que atraíram os associados dos clubes de ciclistas, os quais começaram a se envolver também com outros esportes. O futebol, em particular, despertou a atenção dos ciclistas, quando foi exibido pela primeira vez em Porto Alegre no ano de $1903^{4}$.

O crescimento da prática do futebol contribuiu para o enfraquecimento dos clubes ciclísticos na cidade ainda na primeira década do século $X X^{3,4}$. Depois de um período esmorecedor e de pouca visibilidade do ciclismo, inclusive nos jornais, foram retomadas as competições nos anos de 1930, quando foi fundada a Federação Gaúcha de Ciclismo (FGC), que anos depois incorpora também o motociclismo.

Assim, o presente estudo tem como objetivo historiar desde as primeiras provas ciclísticas em Porto Alegre, passando pelo arrefecimento das disputas, até os anos de 1930, quando são retomadas as provas ciclísticas na cidade.

\section{MÉTODO}

As transformações conhecidas por algumas capitais brasileiras nas décadas iniciais do século $X X$ foram, em várias investigações, perscrutadas por intermédio da imprensa ${ }^{6}$. A aceleração do tempo e o confronto com os artefatos que compunham a modernidade, assim como a difusão de novos hábitos, aspirações e valores, as demandas sociais, políticas e estéticas das diferentes camadas que circulam pelas cidades, eram registradas pelos jornais, também denominados periódicos. A utilização da bicicleta e a prática do ciclismo foram destacadas como parte dos hábitos da vida moderna pela imprensa da época ${ }^{3}$.

Diante de tal cenário, optamos por realizar uma investigação historiográfica de caráter documental, através da análise de fontes impressas, principalmente jornais, que circulavam no Rio Grande do Sul, entre o final do século de 1800 e a primeira metade do século de 1900. Os materiais coletados foram manuseados, fichados, analisados e cotejados, conforme as orientações de Bacellar’, com relação à pesquisa documental.
Ainda, foi utilizado o livro de Licht ${ }^{4}$, o qual consiste na catalogação de reportagens, notas e notícias sobre ciclismo em jornais porto-alegrenses, particularmente, o jornal Correio do Povo. Ressalta-se que, com a intenção de realçar o estudo histórico, os autores optaram por manter a grafia original dos textos reproduzidos em citações diretas, os que, muitas vezes, utilizavam palavras não mais utilizadas atualmente ou com diferentes formatos de escrita.

Cabe referir que o estudo em questão está abarcado pelo projeto “Esporte e Educação Física no Rio Grande do Sul: Estudos Históricos", o qual foi aprovado pelo Comitê de Ética em Pesquisa da UFRGS, sob o número 19261. O ciclismo é uma das práticas pesquisadas, tendo em vista que foi apropriado pelos sul-rio-grandenses a partir da segunda metade do século XIX. Na sequência apresentamos os resultados desta pesquisa histórico-documental.

\section{A CONSTRUC̣ÃO DOS PRIMEIROS VELÓDROMOS EM PORTO ALEGRE}

O primeiro velódromo da cidade de Porto Alegre foi construído pela Radfahrer Verein Blitz (Sociedade Ciclística Relâmpago). Este clube de ciclísticas somente aceitava associados teuto-brasileiros ${ }^{37} \mathrm{e}$, inclusive, a programação das provas ciclísticas era redigida no idioma alemão ${ }^{8}$. O clube recebia críticas, mas mantinha suas práticas e representações culturais de uma identidade teuto-brasileira. Quando foi fundado outro clube de ciclistas, a União Velocipédica, que congregava sócios de diferentes grupos sociais, evidenciou-se conflitos identitários entre os dois clubes. O conflito acirrou-se com o projeto de construção do velódromo da União Velocipédica.

Após um debate de dois meses, em outubro e novembro de 1898 , sobre a melhor localização para a construção do velódromo do primeiro clube de ciclismo de Porto Alegre, a União Velocipédica, criou, no mês de dezembro, uma comissão para tratar do arrendamento e da construção do velódromo ${ }^{9,10}$. Os diretores do clube de ciclismo desejavam construir o velódromo próximo ao Prado Independência (atual Parcão), onde já havia uma pista de corridas. No entanto, a escolha do local sofreu críticas, quanto às muitas ladeiras e a situação problemática das estradas do entorno. Diante disso, cogitou-se o Campo da Várzea, que na época compreendia o terreno onde se localiza atualmente o Colégio Parobé. Por fim, o terreno para o velódromo foi oferecido pelo intendente municipal (prefeito), José Montaury, para arrendamento por nove anos.

As obras de construção do Velódromo da União Velocipédica iniciam em março de 1899, com uma grande festa comemorativa. O projeto do velódromo foi elaborado pelo engenheiro Gustavo Koch, mas o projeto original teve mudanças feitas pelos engenheiros Alfredo Leyraud e Lindolpho Silva. Duas empresas assumiram a responsabilidade pela construção, uma delas construiria a pista e o pavilhão social e a outra colocaria as grades que cercariam o velódromo ${ }^{11}$. A previsão para a constru-

\footnotetext{
${ }^{37} \mathrm{O}$ termo teuto-brasileiro, oriundo da segunda metade do século $\mathrm{XIX}$, define o duplo pertencimento - à etnia alemã e ao Estado brasileiro na qualidade de cidadão ${ }^{15}$
} 
ção e entrega do velódromo foi de quatro meses.

Em decorrência do período de chuvas, houve atraso na obra e o velódromo da União Velocipédica, assim, este foi inaugurado apenas no dia 19 de novembro de 1899. No contrato, a pista constava com 330 metros de extensão, sendo a velocidade da pista prevista para aproximadamente 55 quilômetros por hora ${ }^{12}$. Quando inaugurado, o jornal registrou que o velódromo tinha 17 mil metros quadrados de área, espaço social com iluminação e mobiliário, pista com 333 metros de extensão e as bicicletas, podendo alcançar a velocidade de 70 quilômetros por hora ${ }^{13}$. Quando foi inaugurado o velódromo, a União Velocipédica alcançava 750 sócios $^{14}$.

A inauguração do velódromo da União Velocipédica parece ter despertado o interesse da Radfahrer Verein Blitz em adquirir um novo velódromo. O clube manifestou ao intendente municipal o interesse em adquirir um terreno para a construção de um novo velódromo, nas mesmas condições que a União Velocipédica e em local próximo ao velódromo deste clube. Os dirigentes do clube conhecido como Blitz chegaram até mesmo a realizar medições em um terreno indicado, mas o plano não seguiu adiante ${ }^{15}$. A Blitz decidiu reformar a pista do seu antigo velódromo para que as bicicletas pudessem atingir maiores velocidades ${ }^{16}$.

No início do século XX, no mês de março de 1900 , outro velódromo, com uma nova proposta, foi inaugurado na cidade de Porto Alegre: o Recreio Militar. Este velódromo, localizado onde hoje se encontra o Hipódromo Cristal no Bairro Cristal, pertencia ao $3^{\circ}$ Batalhão da Brigada Militar, seu uso era restrito aos militares. 0 velódromo foi concebido para que os militares aprendessem a usar a bicicleta, neste ambiente; praticar o ciclismo visava realizar o patrulhamento, bem como melhorar a forma de comunicação entre as sedes ${ }^{17}$.

A prática era tão difundida que as instruções sobre a utilização da bicicleta não ocorria apenas nos clubes de ciclismo mas, também, por meio da imprensa. O jornal Correio do Povo, no período de maio a agosto de 1899, publicou três reportagens que abordavam diversos assuntos referentes ao ciclismo. Dentre os temas destaca-se: a bicicleta para a criança e o idoso; a bicicleta para os doentes; exercícios de ciclismo; como se aprende a andar; higiene em um dia de excursão e conselhos em caso de acidentes, durante uma excursão ${ }^{4}$. A segurança dos praticantes de ciclismo era uma preocupação dos clubes de ciclismo, que, por meio do jornal, solicitaram à prefeitura de Porto Alegre a colocação de placas de trânsito semelhantes às existentes na França. Nas placas indicava-se o cuidado com os cães, com as descidas perigosas e com a presença de $\operatorname{carros}^{18}$.

Não era a primeira vez que o jornal Correio do Povo fazia referência a países da Europa, como modelo a ser seguido pelos porto-alegrenses, no que diz respeito às práticas esportivas modernas. Ao referir que o Presidente da República, Campos Sales, estava aprendendo a utilizar a bicicleta no Velódromo Paulista, o fragmento da reportagem do jornal, datado do mês de outubro de 1898, destacava o uso da bicicleta como hábito moderno e vinculado a um capital cultural:

[...] o ilustre presidente da Republica eleito, que aprendia a montar e, segundo os mesmos colegas, mostrava bastante enthusiasmo pelo cyclismo. É que s. ex. viu como na Europa a byciclette é utilizada pelos homens mais notaveis nas artes, nas letras, na indústria, no commercio e na política ${ }^{19}$

Enquanto em São Paulo, desde o final do século XIX, o ciclismo já estava mais difundido, na cidade de Porto Alegre, as provas ciclísticas foram incrementadas no princípio do século $X X$, quando os dois clubes tinham velódromos em boas condições. A prova dos 50 quilômetros na capital ocorreu no ano de 1900; esta foi considerada um marco para o esporte, no cenário sul-rio-grandense. Isso de se deu porque havia uma atmosfera de expectativa que permeava a tentativa do ciclista Oscar Schaitza da Blitz, de quebrar o recorde da prova, que pertencia ao ciclista da União Velocipédica, João Alves. Schaitza diminuiu a marca de Alves em mais de 3 minutos, concluindo a prova em um tempo total de $1 \mathrm{~h} 16 \mathrm{~min} 53 \mathrm{~s}$. No ano seguinte, novamente a União Velocipédica recupera o recorde da prova com o desempenho do ciclista Jacob Aloys Friederichs, que superou a marca anterior reduzindo o tempo para $1 \mathrm{~min} 09 \mathrm{~s}^{4}$.

Os clubes de ciclismo disputavam, além das provas entre si, o número de associados também. No final do ano de 1900, a União Velocipédica possuía 1.117 sócios, destes, $1.039 \mathrm{em}$ atividade e com o pagamento em dia $^{4}$. Já a Blitz, não tinha um número tão significativo de sócios, isto porque, diferentemente da União Velocipédica que congregava imigrantes e descendentes de alemães, italianos e portugueses; a Blitz era um clube muito identificado com os teuto-brasileiros.

Nesta época, ambos os clubes tinham uma boa estrutura com sede social e velódromo, pois arrecadavam valores com os sócios, além de receberem doações de membros destacados da comunidade que apoiavam a prática do ciclismo. Mas, além dos clubes, a intendência municipal (prefeitura) também ganhava dinheiro com o uso da bicicleta por meio dos impostos pagos sobre os veículos. Conforme aviso publicado em jornal: "Pela inspectoria de vehiculos, são intimados os possuidores de bicycletas a trazerem as respectivas chapas de licença em logar visivel, sob pena de multa"20. No ano de 1900, a prefeitura arrecadou impostos sobre de 445 bicicletas. Os clubes de ciclistas tentaram a isenção de pagamento de imposto das bicicletas de seus atletas, entretanto, no ano seguinte (1901), o valor novamente foi cobrado, segundo reportagem do jornal Correio do Povo ${ }^{21}$.

O ano esportivo de 1901 começa com a realização do Campeonato de Resistência no velódromo da Blitz. Inscreveram-se, para esta prova, 10 ciclistas, sendo sete da Blitz e três da União Velocipédica, porém, os ciclistas da União Velocipédica não compareceram ao evento, alegando que a pista do velódromo era muito estreita. Esse fato acentuou ainda mais a rivalidade entre os dois clubes, que também disputavam o encargo de organização do campeonato ${ }^{22}$.

Os ciclistas da União Velocipédica compareceram na edição seguinte, em 1902, do Campeonato de Resistência Rio-Grandense, novamente sediada pela Blitz. As duas primeiras provas ocorreram sem incidentes e os ciclistas da Blitz foram vencedores. Já, a terceira, a mais esperada prova pelo público, e a qual reunia os 
melhores ciclistas de ambos os clubes, foi um tanto tumultuada. Ao final da última volta na pista, o ciclista Friederichs, representante da União Velocipédica, e o ciclista Vitale, que representou a Blitz, chegaram praticamente empatados na linha de chegada.

Havia dois juízes na prova, um de cada clube, os quais divergiram no resultado final. O juiz da Blitz, Strunck, declarou a vitória de Vitale, enquanto que Antonio Mostardeiro, juiz da União Velocipédica, declarou a corrida empatada. Depois de discussões acaloradas entre os representantes dos dois clubes, decidiu-se pela anulação do resultado e outra prova foi realizada. Após 15 voltas na pista do velódromo, o vencedor foi o ciclista Friederichs da União Velocipédica, que foi erguido pelos sócios do clube em comemoração ao resultado. Além disso, soltaram-se foguetes junto à residência de Antonio Mostardeiro, como forma de saudar a sua atuação ${ }^{4}$.

Os clubes de ciclismo, para além do seu esporte exclusivo, começaram a oferecer outras práticas esportivas, em 1903. A União Velocipédica inaugurou um espaço em seu velódromo para a realização de aulas de esgrima e tiro ao alvo, e promoveu, em agosto do mesmo ano, o primeiro campeonato de tiro ao alvo no seu velódromo, com a presença de 28 atiradores ${ }^{23}$. Além disso, o velódromo do clube, que no princípio era palco apenas de provas ciclísticas, permitiu corridas a pé e em sacos, de acordo com o jornal Correio do Povo ${ }^{24}$. A Blitz, por sua vez, promovia em seu velódromo, corridas de atletismo dos associados da Turnenbund (atual Sociedade Ginástica Porto Alegre - SOGIPA), bem como demonstrações de ginástica em seus eventos sociais ${ }^{4}$.

A admissão de novos esportes coincidiu com um período de dificuldades enfrentadas pelos clubes de ciclismo ${ }^{4}$. Na terceira edição do Campeonato de Resistência Rio-Grandense, em maio de 1903, a Blitz não inscreveu atletas e algumas fases eliminatórias acabaram sendo transferidas para outra data. A União Velocipédica, por sua vez, acabou excluindo um atleta de destaque de seu quadro e juntamente com isso ocorreu à renúncia da diretoria do clube. Ainda no ano de 1903, a apresentação de uma novidade esportiva aos porto-alegrenses, também, enfraqueceria nos anos seguintes a prática do ciclismo.

O futebol foi apresentado aos porto-alegrenses por meio de um jogo exibição dos atletas do Sport Club Rio Grande, da cidade de Rio Grande, no velódromo da União Velocipédica, no mês de setembro de 1903. O time de futebol e seus dirigentes foram recepcionados por vários clubes, dentre eles a União Velocipédica e a Blitz, que tinham interesse no novo esporte. Em seguida, aproximadamente uma semana depois do jogo exibição, dois clubes de futebol foram fundados em Porto Alegre na mesma data: o Grêmio Foot-ball Porto Alegrense e o Fuss-Ball Club Porto Alegre ${ }^{25}$.

O Grêmio Foot-ball Porto Alegrense, nos primeiros anos utilizou o velódromo da União Velocipédica para a realização de partidas de futebol. Já, os fundadores do Fuss-Ball Club Porto Alegre, clube que foi criado pela iniciativa de ciclistas da Blitz, receberam um terreno, doado por Luiz Englert, próximo ao Velódromo da Blitz para ser usado como campo de futebol. Os pioneiros da Blitz, gradativamente, trocaram a prática do ciclismo pelo futebol e passaram a organizar torneios de futebol, churrascos e festividades.

Enquanto a Blitz sobrevivia por meio do ciclismo e futebol, a União Velocipédica enfrentava sérios problemas. No mês de janeiro de 1905, ocorreu uma assembleia geral extraordinária com a finalidade de retomar as atividades da União Velocipédica. Foi decidida a extinção dos cargos de diretores e a direção do clube ocorreria por meio de um comitê em que todos os membros teriam igual responsabilidade e obrigações ${ }^{26}$. Além disso, como um dos encaminhamentos da assembleia, foram confeccionados e distribuídos panfletos aos antigos sócios no intuito de que voltassem a frequentar o velódromo ${ }^{27}$. Todavia, a iniciativa surtiu efeito temporário, pois cinco anos depois, em 1910, foi publicada uma nota na seção judiciária do jornal A Federação, divulgando que os bens da União Velocipédica foram penhorados em uma ação da Intendência Municipal (prefeitura) de Porto Alegre ${ }^{28}$. É bem provável, que logo após este fato, o clube encerrou suas atividades. A última nota encontrada sobre a Blitz foi para divulgar um jogo de futebol que aconteceria no campo do clube ${ }^{29}$.

O futebol foi gradativamente ocupando espaços em Porto Alegre, com a criação do Sport Club Internacional (1909), o Esporte Clube Cruzeiro (1913), o Esporte Clube São José (1917) e outros clubes nas décadas seguintes ${ }^{30}$, ocorre um esmorecimento do ciclismo. Contudo, neste panorama, a prática do ciclismo que marcava presença no cenário esportivo, após um hiato de tempo, é retomada na década de 1930.

\section{O CICLISMO REAPARECE EM PORTO ALEGRE}

As provas ciclísticas ganham, novamente, visibilidade na década de 1930 em Porto Alegre. O Club Cyclista Porto Alegrense, fundado posteriormente aos dois primeiros clubes da capital, por exemplo, contribuiu para o reavivamento da prática e foi responsável por realizar provas de ciclismo pelas ruas da cidade no ano de $1931^{31}$. Em outubro do mesmo ano, o Campeonato Estadual de Ciclismo foi promovido em parceria com o jornal Correio do Povo, que ficou responsável pelo oferecimento de uma taça de prata ao ciclista vencedor. Nesta época, além da publicação de reportagens um tanto esparsas sobre os esportes, alguns jornalistas esportivos auxiliavam na organização das competições.

A busca pela prática competitiva do ciclismo voltava a crescer em Porto Alegre e, juntamente com isso, o aprimoramento das regras da modalidade. Em abril de 1933, por exemplo, o Clube Ciclista Rio Grandense, em reunião da diretoria, deliberou sobre os critérios técnicos de classificação interna de seus ciclistas ${ }^{32}$, movimento que impulsionou uma especialização no esporte. Esta associação era considerada um "clube veterano" no ciclismo e se estabeleceu como uma referência para os demais. Desta forma, provavelmente, outros clubes de ciclismo também discutiram os critérios técnicos de classificação dos ciclistas associados.

Em razão da realização de diversos eventos comemorativos da Exposição do Centenário Farroupilha (1895-1935), instalada no Parque Farroupilha (conhecido como Redenção), na cidade de Porto Alegre, o ciclismo ocupou mais espaço nas reportagens dos jornais no ano de $1935^{33}$. Para este evento, no mês de setembro, foi criado um centro de exposições com diversas ativi- 
dades culturais, incluindo algumas práticas esportivas, dentre elas, o ciclismo. A exibição do ciclismo neste expressivo evento apontou para uma nova fase do esporte na capital e no interior e do estado. Ainda em setembro, os jornais começaram a divulgar a competição que ocorreria no mês seguinte.

As provas de ciclismo comemorativas do Centenário Farroupilha contaram com participantes de clubes representando as cidades de Porto Alegre, Pelotas, Rio Grande, Cachoeira do Sul e Santa Maria. Na disputa por clubes, a equipe vencedora foi o Clube Ciclista Pelotense, de Pelotas; na segunda colocação ficou o Clube Ciclista Rio Grandense, de Porto Alegre e a terceira posição foi da Sociedade Ciclista Rio Grandense, de Rio Grande. Outros dois clubes da capital, o Clube Ciclista Bianchi e o Clube Ciclista Esperança, ocuparam, respectivamente, as posições restantes.

As fontes consultadas revelam que os ciclistas de Pelotas e Rio Grande, na maioria das vezes, obtinham melhores resultados em relação aos de Porto Alegre nas competições da década de 1930. “Nas provas do campeonato farroupilha, o maior número de vitorias coube aos pelotenses e rio-grandenses, que se apresentaram bem preparados e não se descuidaram da pratica do salutar desporto"34(p. 5). A reportagem, datada do dia 15 de outubro de 1935, ressalta que as pontuações dos clubes de Pelotas e Rio Grande poderiam ser ainda superiores, caso o número de atletas oriundos de clubes de tais cidades fosse maior ${ }^{35}$.

Conforme o jornal, o ciclismo nas cidades de Pelotas e Rio Grande, além de já estar constituído há bastante tempo, não sofreu com o esmorecimento da prática pelos clubes, como ocorreu no caso de Porto Alegre $^{35}$. No entanto, nos jornais porto-alegrenses, a supremacia dos ciclistas de Pelotas e Rio Grande foi somente retomada em reportagens datadas a partir dos dias 21 e 24 de dezembro de $1935^{34}$, na qual consta um apelo para que os clubes de Porto Alegre organizem-se com o intuito de tornar novamente o ciclismo uma prática esportiva de destaque na capital, o que demonstra a competitividade intermunicipal do período.

É necessario que todos os clubes ciclistas desta capital se organizem devidamente, afim de, nas proximas provas de janeiro, levantar bem alto os creditos e a tradição de Porto Alegre, que foi a vanguardeira do esporte do pedal, com os seus velodromos, ponto de reunião, na época, da nossa sociedade. Corredores de valor temos em Porto Alegre. É preciso que voltem a atividade, afim de reviverem os memoráveis campeonatos passados $^{34}$ (p. 5).

Nesta direção, o Clube Ciclista Esperança que, juntamente com o Clube Ciclista Rio Grandense, congregava na década de 1930 os ciclistas mais destacados de Porto Alegre, promoveu uma passeata. O evento contou com aproximadamente 30 ciclistas, que circularam pelas principais ruas da cidade ${ }^{34}$. Tal movimento dos ciclistas favoreceu a criação de uma entidade que regulamentaria as provas de ciclismo em todo o Rio Grande do Sul: a Liga Gaúcha de Ciclismo em 1935.

Não há informações detalhadas sobre quando a
Liga Gaúcha de Ciclismo (LGC) passou a ser denominada de Federação Gaúcha de Ciclismo (FGC). Talvez a mudança tenha ocorrido no ano de 1937, conforme indícios identificados em uma reportagem datada no mesmo ano, que, além de mencionar os clubes pioneiros no ciclismo porto-alegrense, tece elogios à atuação da FGC:

É notável o desenvolvimento do ciclismo em nossa metropole. $O$ desporto do pedal está revivendo os seus aureos tempos da Blitz e da União Velocipedica, graças á magnifica orientação que the vem imprimindo a novel mas prestigiosa Federação Gaucha de Ciclismo. A mentora do ciclismo gaúcho vem realizando, continuamente, excelentes competições ${ }^{36}$ (p. 44).

Os nomes dos fundadores da LGC eram os mesmos da posterior FGC. Tais nomes também se repetiam nas reportagens que divulgavam as pessoas responsáveis pela organização das competições. Além disso, verificou-se que muitas das empresas que apoiavam a realização de competições pertenciam aos organizadores dos eventos ${ }^{37}$.

A empresa "Henke Irmãos", por exemplo, estava envolvida com o ciclismo por meio de membros da família que disputavam as competições. Francisco Henke e Lindolfo Henke, não apenas eram praticantes, mas, além disso, atuaram como dirigentes na primeira gestão da FGC. As crianças desta mesma família também tinham envolvimento com o ciclismo, participando de provas exclusivas para meninos e meninas. Como exemplo, trazemos o caso de Nera Henke, Olinda Henke, Neri Henke, Norma Henke e de Henrique Francisco Henke ${ }^{38}$. Nas competições para crianças, cada gênero era subdividido por faixa etária em três categorias, a saber: a) até sete anos; b) de oito até dez anos; c) de onze até doze anos ${ }^{39}$.

O sobrenome Henke, além de estar associado ao ciclismo, também era o nome da empresa que pertencia à família, "Henke Irmãos", a qual era distribuidora de pneus e câmaras de bicicleta da marca Dunlop. Vale destacar que a empresa Dunlop foi criada no ano de 1888, depois que o veterinário escocês John Boyd Dunlop inseriu um tubo de ar nos aros do triciclo de seu filho, criando a câmara de ar e o pneu "pneumático" no ano de 1887. Esses novos pneus eram mais leves e confortáveis que os anteriores feitos de madeira ou ferro ${ }^{40}$.

Além dessa empresa, outras patrocinavam as disputas do ciclismo e/ou ofereciam prêmios destinados aos vencedores. As premiações não eram em dinheiro, mas, sim, em presentes ofertados pelas empresas apoiadoras e troféus fabricados pelas companhias metalúrgicas. Assim estas faziam sua divulgação, pois algumas provas ciclísticas recebiam o nome da empresa patrocinadora.

As provas ciclísticas eram realizadas em diferentes lugares, no entanto, a pista de ciclismo situada no Parque Farroupilha, localizada ao redor do lago, próximo da Avenida João Pessoa, era considerada uma das melhores. Esta pista, no mês de abril de 1936, foi nivelada pela iniciativa do Comissariado Geral da Exposição Farroupilha. O percurso de cada volta tinha aproximadamente 700 metros e as características da pista favoreciam a obtenção de velocidades altas, já que não existiam curvas muito acentuadas e o piso era 
considerado firme ${ }^{40}$.

A pista do Parque Farroupilha era utilizada, principalmente, pelo Clube Ciclista Esperança e Clube Ciclista Rio Grandense. O primeiro tinha sede na Rua José do Patrocínio, número 350, enquanto que o segundo estava localizado na Rua Voluntários da Pátria, número 51. Ambos tinham as sedes localizadas na região central, próximo ao Parque Farroupilha, favorecendo o deslocamento tanto dos ciclistas quanto dos espectadores até o espaço de competição ${ }^{41}$.

O número de ciclistas e espectadores nas provas variava, como mostra a reportagem de jornal publicada no mês de julho de 1936, quando referiu à presença de 82 atletas em uma competição ciclística promovida pela $\mathrm{LGC}^{38}$. Ainda no mesmo ano, em outubro, na edição da $1^{\text {a }}$ Volta Ciclística de Porto Alegre, anotou-se a participação de cerca de 50 ciclistas e aproximadamente quatro mil pessoas, prestigiando a competição. Também importa destacar que esta prova de ciclismo contou com a primeira transmissão de rádio através da Rádio Farroupilha ${ }^{42}$. Esta prova ciclística pode ser considerada um marco histórico no calendário de competições, pois ocorreu anualmente de 1936 até 1984 Após uma lacuna de 10 anos, retornou ao calendário de provas ciclísticas em 1995 até o ano de 2006. As edições de 2007 e 2008 estavam previstas, mas não foram efetivadas por problemas na gestão da Federação Gaúcha de Ciclismo. A entidade não promove mais o evento, no entanto, atualmente, outra competição tem destaque no calendário anual da federação: a Volta Ciclística Internacional do Rio Grande do Sul.

Os eventos, além das provas ciclísticas, também congregavam os participantes em atividades festivas. Nos encontros pós-competições, diferentes tipos de comida e bebidas eram oferecidas aos associados. Segue um registro noticiado pelo jornal: "Às 11 horas, na sede do Clube Esperança, foi pela sua diretoria oferecido aos seus associados uma mesa de frios e chopp, comparecendo a esta festa, parte dos membros da diretoria da Liga"43 (p. 4).

Conforme os jornais consultados, em 1937, a LGC torna-se a Federação Gaúcha de Ciclismo (FGC), a qual tinha como meta a construção de uma sede definitiva, contando com o apoio de indústrias e lojas de materiais para bicicletas. No mês de abril do referido ano, foi divulgado o local de instalação da sede da FGC: em uma sala do prédio do Banco Nacional do Comércio, localizado à Rua Sete de Setembro, junto à Praça da Alfândega, no Centro Histórico de Porto Alegre (atualmente o espaço é ocupado pelo Santander Cultural) ${ }^{44}$.

A FGC, além da sede própria, também desejava ampliar o número de clubes filiados, pois no interior do estado, nas cidades de Jaguarão, Cachoeira do Sul, Novo Hamburgo e Cruz Alta eram criados novos clubes ${ }^{45}$. Até o ano de 1937, os seguintes clubes eram filiados à Federação Gaúcha de Ciclismo: Clube Ciclista Esperança, Clube Ciclista Rio Grandense, Grêmio Ciclista Jupiter, Atlético Sigma Ciclista e o Clube Ciclista Porto Alegrense, todos da capital, e a Sociedade Ciclista Angola, de Rio Grande, e o Clube Ciclista Pelotense, de Pelotas ${ }^{35}$.

Com o aumento do número de clubes filiados, notou-se que as provas ciclistas tiveram o incremento de participantes. Na primeira prova do ano de 1937, cerca de 100 ciclistas disputaram as 11 categorias no evento de início de temporada. Destaca-se, por exemplo, a prova de velocidade, a prova de longa duração, as disputas de meninos e meninas, a disputa de principiantes, a prova de veteranos e a prova de revezamento ${ }^{46}$.

Os ciclistas de Porto Alegre, no geral, tinham resultados inferiores aos dos clubes da cidade de Pelotas nas provas. Diante dessa situação, a FGC, formou uma seleção com atletas dos clubes de Porto Alegre, escoIhidos conforme critério técnico. Em seguida, a equipe porto-alegrense teve treinamento específico, visando melhorar seu desempenho. A FGC tinha como finalidade excursionar com a equipe de ciclistas porto-alegrenses até a cidade de Pelotas, no mês de maio de 1937, a fim de disputar provas com os clubes de Pelotas e Rio Grande.

Talvez, a FGC tenha tomado esta decisão visando diminuir a diferença de nível técnico entre os ciclistas de clubes da capital em relação às outras cidades. $O$ ciclismo na capital do Rio Grande do Sul ficou estagnado durante muitos anos, inclusive porque dirigentes do ciclismo migraram para os clubes de futebol, no início do século $X X$. Outro motivo para esta iniciativa da fundação da FGC foi porque a maioria dos dirigentes da entidade eram de clubes de Porto Alegre, ainda que houvesse alguma representatividade de administradores dos clubes de Pelotas e Rio Grande, eles eram a minoria. É possível, também, que a FGC tivesse interesse em disseminar o esporte por meio de provas.

\section{A FEDERAC̣ÃO GAÚCHA DE CICLISMO INCORPORA OUTRA PRÁTICA}

A Federação Gaúcha de Ciclismo incorporou, no mês de agosto de 1937, a prática do motociclismo, decorrendo deste fato a alteração do nome da entidade para Federação Gaúcha de Ciclismo e Motociclismo (FGCM). É provável, que esta coligação de esportes tenha ocorrido devido a maior sintonia da FGC com o Moto Clube do Brasil, entidade responsável pelo motociclismo no país. Diferentemente da relação estremecida da FGC com a Federação Ciclística Brasileira (FCB), responsável por dirigir o ciclismo no âmbito nacional.

A FGCM filiou-se somente ao Moto Clube do Brasil, pois a FCB impôs uma série de exigências que não puderam ser atendidas por parte da entidade sul-rio-grandense. Mesmo que, o ciclismo continuasse a ser a principal prática esportiva, frequentemente, o motociclismo estava presente nos eventos organizados pela federação ${ }^{47}$. Ainda no mês de agosto, a FGCM filiou-se à Confederação Brasileira de Desportos (CBD), entidade não governamental que regulamentava o esporte no $\mathrm{Brasil}^{48}$.

A FGCM completou dois anos de existência no mês de outubro de 1937, e também comemorou a filiação de dois novos clubes: o Moto Clube Rio-Grandense e o Clube Ciclista Leopoldense. O Moto Clube Rio-Grandense, de Porto Alegre, tinha o motociclismo como esporte prioritário, enquanto que o Clube Ciclista Leopoldense, de São Leopoldo, dedicava-se a prática do ciclismo. Somando-se esses dois novos clubes, a FGCM contava com o total de nove clubes filiados, destes, seis sediados em Porto Alegre, um na cidade de Pelotas, um em Rio Grande e outro em São Leopoldo ${ }^{49}$.

A FGCM fortalecia sua atuação não apenas pela filiação de novos clubes, mas também, com o incentivo 
a participação de ciclistas porto-alegrenses em provas realizadas em outros estados, especialmente Paraná, Rio de Janeiro e São Paulo. Também se tornava mais recorrente, a participação de atletas oriundos de outros estados nas provas ciclísticas em Porto Alegre. Na disputa da II Volta da Cidade de Porto Alegre, por exemplo, participaram além de atletas porto-alegrenses, representantes de clubes de ciclismo de São Leopoldo, Rio Grande, Pelotas, Curitiba e Rio de Janeiro ${ }^{50}$.

No final dos anos 1930, o ciclismo sofreu um abalo com o encerramento das atividades do jornal $A$ Federação, no final do ano de 1937, o qual divulgava, comumente, as provas e acontecimentos do ciclismo. Além disso, evidenciou-se a interrupção das reportagens sobre o ciclismo na Revista do Globo, a última reportagem foi publicada no ano de $1939^{51}$. Apenas no ano de 1943, novamente o ciclismo foi assunto da revista, por meio de uma reportagem de três páginas ilustradas com fotografias, que referia o desenvolvimento da prática na cidade de Porto Alegre na transição dos séculos XIX e $X X$. O registro também revelava as dificuldades que o ciclismo enfrentava. “Hoje o desporto do pedal só é praticado nas ruas e estradas. Não há mais velódromos e a situação financeira dos clubes é precaríssima" 52 ( $p$. 39). Ainda apresentava uma comparação entre a prática do ciclismo na transição dos séculos XIX e XX com as décadas de 1930 e 1940:

Pouco a pouco, as competições de rua reapareceram sem que, no entanto, siquer fosse construída uma única pista especial, por modesta, na cidade que já possuíra duas, uma das quais equiparada às melhores do mundo. O ciclismo lutou desesperadamente para voltar a ser o "esporte das multidões" que era antigamente. Não o conseguiu e não o conseguirá jamais. Desde o nível social de seus praticantes até a situação financeira de seus clubes, a disparidade entre o passado e o presente é enorme ${ }^{52}$ (p. 59).

Além da extinção do jornal que mais publicava sobre o ciclismo na cidade e a falta de visibilidade ao esporte pelos outros jornais, o fechamento dos velódromos e a precária situação financeira dos clubes, bem como, a emergência de outras práticas esportivas nos clubes são fatores que contribuíram com o enfraquecimento do ciclismo na cidade de Porto Alegre.

\section{CONSIDERAÇÕES FINAIS}

Reconstruir o passado, já vivenciado e as memórias, é sempre uma tarefa complexa, pois estamos sujeitos ao achado de novas informações que incitam a contar uma nova versão da história. Neste artigo, buscamos narrar uma versão acerca de como ocorriam as provas ciclísticas na cidade de Porto Alegre. Para tanto, utilizamos principalmente jornais como fonte de informações, a fim de sistematizar uma versão verossímil dos acontecimentos.

A capital sul-rio-grandense teve durante o final no século XIX e início do $X X$ dois clubes ciclísticos, a Blitz e a União Velocipédica, os quais promoviam disputas acirradas em espaços próprios para a prática: os velódromos. No entanto, com a popularização de um novo esporte da época conhecido por futebol, e devido a problemas de gestão dos próprios clubes, houve o declínio e quase desaparecimento das provas ciclísticas. Entretanto, na década de 1930, houve o resurgimento da prática ciclística. Percebe-se, desta forma, como a história colabora para conhecermos a realidade do passado e permite que identifiquemos elementos do que já existiu, porém reorganizados de maneira a resurgir em outro formato.

Naquele período, década de 1930, os clubes de ciclismo pioneiros sediados na capital já não existiam mais, mas a prática tinha ultrapassado os limites de Porto Alegre. Com um estimulo originado da imprensa, esta prática começa a reaparecer no cenário, pois as notícias acerca das práticas voltavam a circular nos jornais, o que apontava um novo fôlego para o esporte. Os veículos de comunicação de então destacavam o Parque Farroupilha na capital sul-rio-grandense como o novo espaço para as disputas ciclísticas. Assim, os jornais colaboraram para um reaparecimento do ciclismo no cenário esportivo porto-alegrense.

Com o destaque nos jornais, a prática volta a se disseminar pela cidade. A necessidade por uma entidade própria da modalidade torna-se latente. Quando, em 1935, a Liga Gaúcha de Ciclismo foi fundada, porém logo teve seu nome modificado para Federação Gaúcha de Ciclismo (FGC). Tal feito demonstra a sistematização do campo esportivo do ciclismo no Rio Grande do Sul, visto que entidade congregou e superintendia os clubes da capital e do interior do estado, com destaque para o clube da cidade de Pelotas, o qual possuía atletas distinguidos nas provas. Além disso, as competições eram destaques em jornais, o que colaborou para que o número de clubes vinculados à entidade viesse a aumentar, com a vinculação, principalmente, de clubes de outras cidades do estado.

Possivelmente, devido a esse crescimento e visando expandir os espaços de poder e domínio, ainda na mesma década, a FGC tornou-se Federação Gaúcha de Ciclismo e Motociclismo (FGCM). A incorporação da nova prática aconteceu a partir de uma boa relação da FGC com o Moto Clube do Brasil e, com isso, novos clubes de ciclismo e motociclismo se filiaram a entidade. Contudo, o cenário profícuo não se perpetuou, quando ao final da década de 1930, as reportagens sobre ciclismo diminuíram novamente, enfraquecendo a prática mais uma vez. Isto também ocorreu porque o jornal A Federação, que divulgava diversas notas sobre esportes, foi extinto.

Assim, se percebe que a trajetória do ciclismo passou por sinuosidades, com surgimento, enfraquecimentos e resurgimentos. De forma que o atual destaque jornalístico da prática, assim como a grande adesão de praticantes, não é original, apesar de suas especificidades vinculadas ao contexto dos períodos em questão, transição do século de 1800 para o de 1900, década de 1930 e a contemporaneidade.

\section{REFERÊNCIAS}

1. Vieira S, Freitas A. O que é Ciclismo: História, Regras e Curiosidades. Rio de Janeiro: Casa da Palavra, 2007.

2. Schetino AM. Pedalando na Modernidade: a bicicletas e o 
ciclismo no Rio de Janeiro e em Paris na transição dos séculos XIX-XX. Dissertação (Mestrado em História Comparada) Universidade Federal do Rio de Janeiro, IFCS, Rio de Janeiro, 2007.

3. Dreissig RM. O início da prática do ciclismo em Porto Alegre e sua relação com o jornalismo. Monografia (Especialização em Jornalismo Esportivo) - Faculdade de Biblioteconomia e Comunicação, Universidade Federal do Rio Grande do Sul, Porto Alegre, 2012.

4. Licht H. Ciclismo no Rio Grande do Sul (1869-1905). Porto Alegre: Editora UFRGS, 2002.

5. Frosi TO, Cruz LL, Dreissig RM, Mazo JZ. A prática do ciclismo em clubes de Porto Alegre/RS. Pensar a Prática (UFG) 14 (3), 1-18, 2011.

6. Luca TR. A grande imprensa na primeira metade do século XX. In: Luca TR, Martins AL (Org.). História da Imprensa no Brasil. São Paulo: Contexto, 2008, 149-75.

7. Bacellar C. Fontes documentais: uso e mau uso dos arquivos. In: Pinski C. (Org.). Fontes históricas. São Paulo: Contexto, 2010, p. 23-80.

8. Impresso em alemão. Correio do Povo. Porto Alegre, 19 fev.1899.

9. Assemblea Geral. Correio do Povo. Porto Alegre, 29 fev.1898.

10. Criticas. Correio do Povo. Porto Alegre, 23 nov. 1898.

11. Pedra Fundamental. Correio do Povo. Porto Alegre, 12 mar. 1899.

12. Assignado Contracto. Correio do Povo. Porto Alegre, 28 jan.1899.

13. Inauguração do Velódromo. Correio do Povo. Porto Alegre, 19 nov. 1899.

14. Matrícula. Correio do Povo. Porto Alegre, 24 set.1899.

15. Seyferth, G. A identidade teuto-brasileira numa perspectiva histórica. In: Mauch, C.; Vasconcellos, N. Os Alemães no sul do Brasil: cultura, etnicidade, história. Canoas: Ulbra, 1994

16. Pretende Adquirir. Correio do Povo. Porto Alegre, 28 nov. 1899.

17. Entrou em Obras. Correio do Povo. Porto Alegre, 02 fev. 1900.

18. Recreio Militar. Correio do Povo. Porto Alegre, 10 mar. 1900.

19. Placas de Sinalização. Correio do Povo. Porto Alegre, 21 maio 1899.

20. Campos Salles Cyclista. Correio do Povo. Porto Alegre, 21 out. 1898.

21. Pela Inspectoria. Correio do Povo. Porto Alegre, 25 mar. 1900

22. Imposto sobre Bicycleta. Correio do Povo. Porto Alegre, 14 fev. 1901.

23. Campeonato de Resistência. Correio do Povo. Porto Alegre, 22 jan.1901.

24. Torneio de Tiro ao Alvo. Correio do Povo. Porto Alegre, 25 ago.1903.

25. Notas Sportivas. Correio do Povo. Porto Alegre, 21 fev.1904.

26. Amaro Júnior J. Almanaque Esportivo do Rio Grande do Sul. Porto Alegre: Tipografia Esperança, 1942.

27. Assembleia Extraordinária. Correio do Povo. Porto Alegre, 22 jan. 1905.

28. Comunicado. Correio do Povo. Porto Alegre, 05 fev. 1905.
29. Secção Judiciária. A Federação. Porto Alegre, 30 set.1910.

30. Football - matchs, A Federação, Porto Alegre, 17 out. 1910.

31. Mazo JZ et al. Associações Esportivas no Rio Grande do Sul: lugares e memórias. Novo Hamburgo: Feevale, 2012.

32. Corrida de Cyclistas. Correio do Porto Alegre, 15 set.1930.

33. Clube Ciclista Rio Grandense. A Federação. Porto Alegre, 6 abr.1933.

34. Ceroni GC. A exposição do centenário da Revolução Farroupilha nas páginas dos jornais Correio do Povo e A Federação. Dissertação (Mestrado em História) - Pontifícia Universidade Católica do Rio Grande do Sul, Porto Alegre, 2009.

35. Passeata do Clube Ciclista Esperança. A Federação. Porto Alegre, 21 dez. 1935.

36. Campeonato Farroupilha de Ciclismo. A Federação. Porto Alegre, 15 out. 1935

37. Notável o Desenvolvimento do Ciclismo. A Federação. Porto Alegre, 01 jan. 1937.

38. Grandes Provas Ciclísticas em Comemoração ao Centenário Farroupilha. A Federação. Porto Alegre, 17 set.1935.

39. Provas de Ciclismo no Parque da Exposição Farroupilha. A Federação. Porto Alegre, 20 jul. 1936.

40. Sensacionais Corridas de Bicicleta realizadas ontem, no Parque de Exposição Farroupilha. A Federação. Porto Alegre, 23 nov.1936.

41. Dunlop Pneus. Sobre a Dunlop. Porto Alegre. Disponível em: <http://dunloppneus.com.br/sobre-a-dunlop/>. Acesso em: 12 abr. 2014.

42. Com valiosos prêmios, entre eles uma bicicleta de corrida. A Federação. Porto Alegre, 14 abr. 1936.

43. Uma Importante Competição de Ciclismo. A Federação. Porto Alegre, 17 abr. 1937.

44. Pelo Ciclismo. A Federação. Porto Alegre, 24 dez. 1935.

45. Federação Gaúcha de Ciclismo vai abrir, domingo, a sua temporada de 1937. A Federação. Porto Alegre, 16 abr. 1937.

46. Com uma passeata a ser efetuada. A Federação. Porto Alegre, 22 fev. 1937.

47. Uma Importante Competição de Ciclismo. A Federação. Porto Alegre, 22 maio 1937.

48. O Interessante Certame. A Federação. Porto Alegre, 20 jul. 1937.

49. Mais uma entidade estadual filiada à C.B.D..A Federação. Porto Alegre, 28 ago. 1937.

50. Vitoriosa entidade que dirige. A Federação. Porto Alegre, 19 out.1937.

51. O Desporto do Pedal. A Federação. Porto Alegre, 25 out.1937.

52. Mazo JZ. Catálogo O Esporte e a Educação Física na Revista do Globo. Porto Alegre: PUCRS, 2004.

53. Decadência do Ciclismo. Revista do Globo. Porto Alegre, 10 jul. 1943. 